\title{
A APLICAÇÃO DA LEI DE ACESSO À INFORMAÇÃO NO SÍTIO ELETRÔNICO DA PREFEITURA DE FRUTAL
}

Mônica de Sousa Alves²

Marcelo Pessoa ${ }^{3}$

\section{Resumo}

O presente artigo analisa a aplicabilidade da Lei 12.527 de 18 de novembro de 2011, conhecida como Lei de Acesso à Informação (LAI), no sítio eletrônico da Prefeitura Municipal de Frutal, município do Estado de Minas Gerais. Trata-se de um estudo exploratório, de natureza quantitativa ${ }^{1}$ e de corte transversal. A pesquisa faz uma correlação da Lei com o avanço das Tecnologias de Informação e Comunicação (TICs), que facilita o cumprimento da LAI na obrigatoriedade da divulgação dos dados em sítios oficiais na internet. No entanto, observa-se que essas ferramentas, neste estudo de caso, são pouco utilizadas, principalmente para o exercício da transparência ativa e para interação com os munícipes.

Palavras-chave: Acesso à Informação; Sítio Eletrônico; Transparência

\section{Introdução}

O Brasil, nos últimos 05 (cinco) anos, vive uma transformação democrática, com o envolvimento mais crítico, ativo e participativo dos cidadãos nas ações políticas e sociais. Protestos populares marcaram o ano de 2013, quando centenas de brasileiros, principalmente nas capitais do país, foram às ruas para insurgir contra os aumentos nas tarifas de transporte público. Em 15 de março de 2015, os brasileiros tomaram novamente as ruas, em nova ação de protesto, reunindo quase 1 (um) milhão de pessoas nos 26 Estados do país e no Distrito Federal (Folha de S. Paulo - 15 de março de 2015).

Essas ações ocorreram no mesmo nexo temporal da aprovação e vigência da Lei de Acesso à Informação (LAI)- Lei 12.527/2011, que veio para garantir aos atores sociais mais informações e controles sobre os agentes da administração pública, o que permite uma participação, mesmo que sem envolvimento direto, na gestão e governança públicas.

\footnotetext{
${ }^{1}$ Trabalho apresentado no DT 5 - Rádio, TV e Internet do XX Congresso de Ciências da Comunicação na Região Sudeste, realizado de 19 a 21 de junho de 2015.

²Aluna do curso de Pós-Graduação de Gestão Pública da UEMG, e-mail:monicaalves.jornalista@gmail.com

3Orientador do programa de Pós-Graduação da FaPP, e-mail:mpmarcelopessoa@ yahoo.com.br
} 
Historicamente, é importante relembrar a Lei de $\mathrm{n}^{\mathrm{o}} 3.420$, de 14 de março de 1964, como o marco da proposta de tornar obrigatória a publicidade nas gestões públicas, destacando seu artigo $1^{\circ}$, que dispõe sobre o controle dos orçamentos, estabelecendo regras à transparência das receitas e despesas dos entes da Federação. Soma-se a este contexto, o artigo 75 da Lei 4.320/64, que acondiciona o controle de execução orçamentária e, em seus parágrafos $1^{\circ}$ e $2^{\circ}$, rege sobre a legalidade dos atos e a responsabilidade sobre os agentes públicos. Nessa mesma Lei, nos artigos subsequentes, são nomeadas diretrizes para o controle interno e externo da execução orçamentária.

No traçar dessa linha do tempo, temos a Constituição de 1988, que aprofunda o controle social da administração pública com foco maior no acesso aos dados das instituições públicas, tratado como um direito do cidadão. No artigo $5^{\circ}$, incisos XXXIII está clara a obrigatoriedade de acesso aos dados dos órgãos públicos, como direito de qualquer cidadão, ressalvando somente aquelas informações de interesse de segurança da sociedade e do Estado.

Ainda no âmbito da Constituição Federal de 1998, observam-se no artigo 37, os princípios da publicidade e eficiência e, no artigo 70, que trata do controle da fiscalização contábil, financeira, orçamentária, operacional e patrimonial dos agentes, quanto à sua legalidade, legitimidade etc., e que ainda estabelece a obrigatoriedade da prestação de contas de qualquer pessoa física ou entidade pública que faça uso do dinheiro público.

$\mathrm{Na}$ conclusão do histórico acima, em que se relatam os avanços legais da garantia de transparência nas ações públicas, também se inclui, de uma forma indireta, a Lei de Responsabilidade Fiscal (LRF) - Lei Complementar ${ }^{\circ} 101$, de 04 de maio de 2000, que garantiu maior controle social na utilização dos recursos públicos e na sua divulgação de forma mais clara e com uma linguagem de fácil compreensão.

No entanto, o grande marco para o combate à corrupção e contribuição da consolidação da democracia, com a obrigatoriedade das transparências ativa e passiva nas ações dos poderes constituídos, estabeleceu-se com a entrada em vigor da Lei $12.527 / 11$.

A partir de então, os poderes constituídos foram forçados a se informatizarem e fazerem uso das ferramentas da internet, para o cumprimento dos artigos da LAI e, ao mesmo tempo, para melhorar a eficiência dos serviços públicos e reduzir custos para a sua divulgação. 
Mesmo os municípios de menor porte (com exceção daqueles com menos de 10.000 habitantes) tiveram que implementar soluções baseadas nas ferramentas tecnológicas.

Vislumbra-se aí, a utilização das Tecnologias de Informação e Comunicação (TICs) para implantação dos sítios eletrônicos, para que neles possam ser inseridos o "Portal da Transparência e/ou Acesso à Informação". Trata-se de uma das ferramentas mais eficazes e rápidas para prover aos munícipes amplo acesso às informações públicas enquanto fomenta-se a participação popular na gestão pública, permitindo uma divulgação proativa em uma seção específica.

De acordo com o $\S 2^{\circ}$, do art. $8^{\circ}$, da Lei de Acesso à Informação, os órgãos e entidades públicas deverão utilizar todos os meios e instrumentos legítimos de que dispuserem para o cumprimento da divulgação dessas informações, "sendo obrigatória a divulgação em sítios oficiais na internet”.

Para Takahashi (2007, p. 239, grifo do autor) "talvez o principal ganho que a internet tenha propiciado ao setor público tenha sido a viabilização dos serviços de governo eletrônico. A cada dia, novos serviços são incorporados ao leque disponível para os cidadãos”.

Seguindo essa premissa, a forma de utilização dos sítios eletrônicos em âmbito municipal, como ferramenta para o cumprimento da LAI, constitui um elemento relevante para ser investigado, pois para todos os poderes constituídos, que fazem uso de recursos públicos, a publicidade passou a ser considerada regra e o sigilo exceção. E conforme prevê o Artigo 216, parágrafo $2^{\circ}$, é de responsabilidade da administração pública a gestão dos documentos e dados e a sua disponibilização de forma que facilite a consulta.

Caso seja de interesse dos gestores públicos, conforme afirmou Umeoka (2004), a internet tem uma gama a cada dia mais variada de ferramentas que permitem que os sítios eletrônicos dos órgãos públicos sejam uma plataforma inteiramente democrática e participativa. Isso permite uma gestão transparente e realmente a serviço do cidadão, com troca de informações e compartilhamento de instruções, além da prestação de contas diárias dos destinos dos recursos públicos, sua forma de contratação e aplicação.

Por isso, para este artigo, foi realizada uma pesquisa no sítio eletrônico da Prefeitura Municipal de Frutal. Nele, relataremos os procedimentos metodológicos, os dados levantados e as considerações das análises feitas. 


\section{Metodologia}

Na busca de dados para este artigo, foi realizada uma investigação criteriosa do sítio eletrônico da Prefeitura Municipal de Frutal, como uma referência empírica. No sítio eletrônico, vemos que Frutal está localizado no Triângulo Mineiro, no Estado de Minas Gerais, na região do Baixo Vale do Rio Grande. Sua economia é voltada para a agropecuária, com a criação de gado de leite e corte e produções agrícolas de abacaxi, soja, milho, mamão e laranja, predominando, atualmente, o cultivo da cana-de-açúcar, com a implantação de duas usinas de açúcar e etanol (FERREIRA, 2002).

Este trabalho é um estudo exploratório e descritivo. Os critérios de usabilidade, funcionalidade e portabilidade não foram analisados nesta pesquisa, uma vez que o foco da mesma é verificar o cumprimento dos dispositivos da Lei de Acesso à Informação (LAI) na transparência das informações, na assiduidade dos dados disponibilizados e na interatividade com os munícipes.

A pesquisa foi realizada no período de $1^{\circ}$ dezembro de 2014 a 19 março de 2015, no sítio eletrônico da Prefeitura Municipal de Frutal, encontrado no endereço na internet http://www.frutal.mg.gov.br. Para o registro das informações coletadas nos sites foi elaborado um protocolo observacional - Planilha4 (CRESWELL, 2007), estruturada de forma a registrar a disponibilidade ou indisponibilidade na forma online dos Serviços e Informações. Observar, segundo Triviños (2008), é destacar de um conjunto as suas características. Para tanto, como técnica de coleta de dados, segundo Selltiz et al (1975) e Richardson (2008) a observação deve ser planejada e registrada, de modo que possa ser submetida a verificações e controles de validade. Tradicionalmente, a observação é classificada como método qualitativo, embora, segundo Richardson (2008), dependendo da direção dada na pesquisa, ela pode ser quantificada, como pode ser conjugada a outras técnicas de coleta de dados.

Utilizando uma Planilha, como objeto para controle das observações, que serviu como parâmetro (Resposta Sim), quando a informação ou serviço eram disponibilizados e, (Resposta Não) quando não encontrados e também quando eram descritos no menu, mas não havia conteúdo disponível (link vazio). Consideramos a pesquisa de corte transversal, visto que a coleta dos dados foi realizada apenas uma vez, em um período determinado (GONÇALVES; MEIRELLES, 2004). 


\section{Apresentação E Discussão Dos Resultados}

Neste tópico, apresentaremos os resultados levantados sobre a problematização desta pesquisa, com a identificação das informações e serviços disponíveis ou não aos cidadãos no sítio eletrônico da Prefeitura de Frutal.

Na primeira análise, observou-se que o sítio eletrônico não utiliza as ferramentas disponíveis pela TICs para criar mecanismos de interatividade com a sociedade. Notouse também que não existe um link com perguntas e respostas (mais recorrentes), que facilitaria o acesso dos cidadãos a dúvidas frequentes e que são cobrados na LAI.

Neste mesmo aspecto, observou-se que as dúvidas dos munícipes bem como as respostas oriundas dos departamentos responsáveis, não são disponibilizadas para os internautas, impedindo assim um tratamento coletivo ao tema ou mesmo ao debate.

Não foi encontrada uma pesquisa de avaliação dos serviços oferecidos pelo Poder Público Municipal que, caso fosse explorada, serviria como parâmetro para melhoria e adaptações (pensar de outro cidadão).

Durante pesquisa, não se deparou com dificuldades nas condições de navegação ou de busca de informações quando elas existem. A tecnologia parece não ser o problema. No entanto, quando a análise se volta para o accountability (palavra sem definição em português), evidencia-se a não disposição de dados e informações de fácil compreensão relativas à forma de utilização e aplicação dos recursos públicos. Nota-se que o enfoque maior está na promoção das ações governamentais em detrimento da transparência de como é investido o dinheiro público, em disposição clara, de fácil entendimento e acompanhamento.

Figura 1 - Capa do sítio eletrônico da Prefeitura

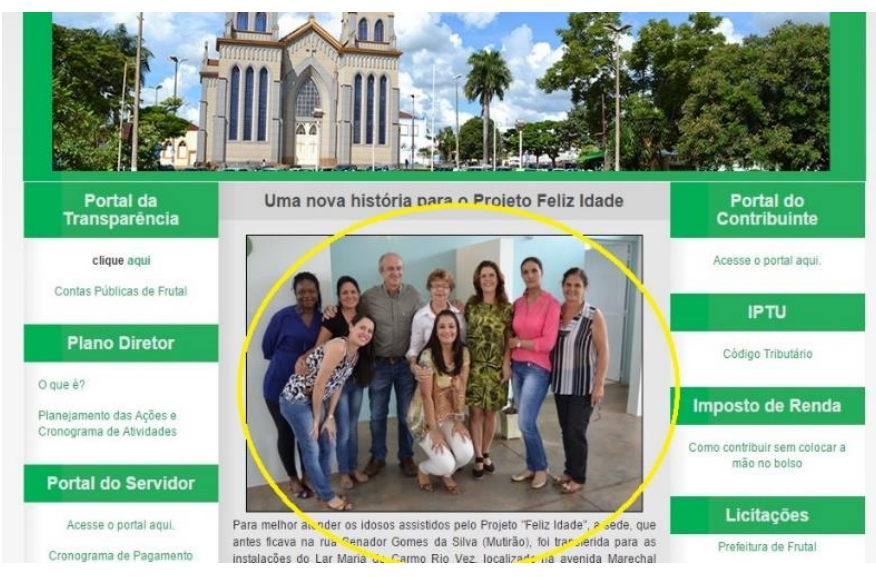

Fonte: http://www.frutal.mg.gov.br/, acessado em 11 de março de 2015 
A capa do sítio eletrônico da Prefeitura de Frutal de 11 de março de 2015 mostra como destaque a foto do gestor municipal e matéria jornalística de promoção de suas ações. Não existe uma sequência de informações quanto aos cronogramas financeiros, não há qualquer justificativa sobre a não apresentação dos mesmos.

Figura 2 - No relatório de Prestação de Contas de 2013.

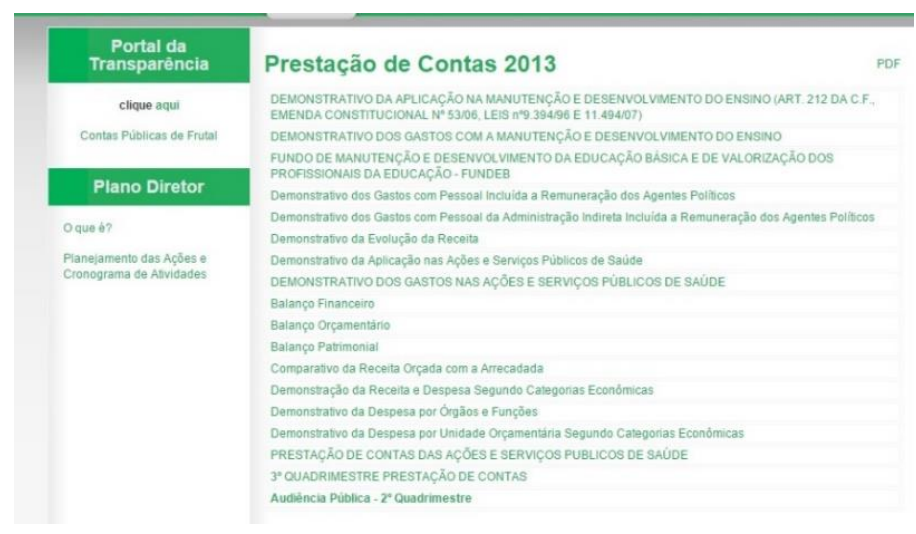

Fonte: http://www.frutal.mg.gov.br/Financas-e-Planejamento/prestacao-de-contas2013.html, acessado em 10 de fevereiro de 2015

Na página do Portal Transparência, na Prestação de Contas de 2013, não estão disponibilizadas as Folhas de Pagamento. Não existe uma sequência de informações quanto aos cronogramas financeiros, não há qualquer justificativa sobre a não apresentação dos mesmos.

Figura 3 - Na Prestação de Contas de 2014.

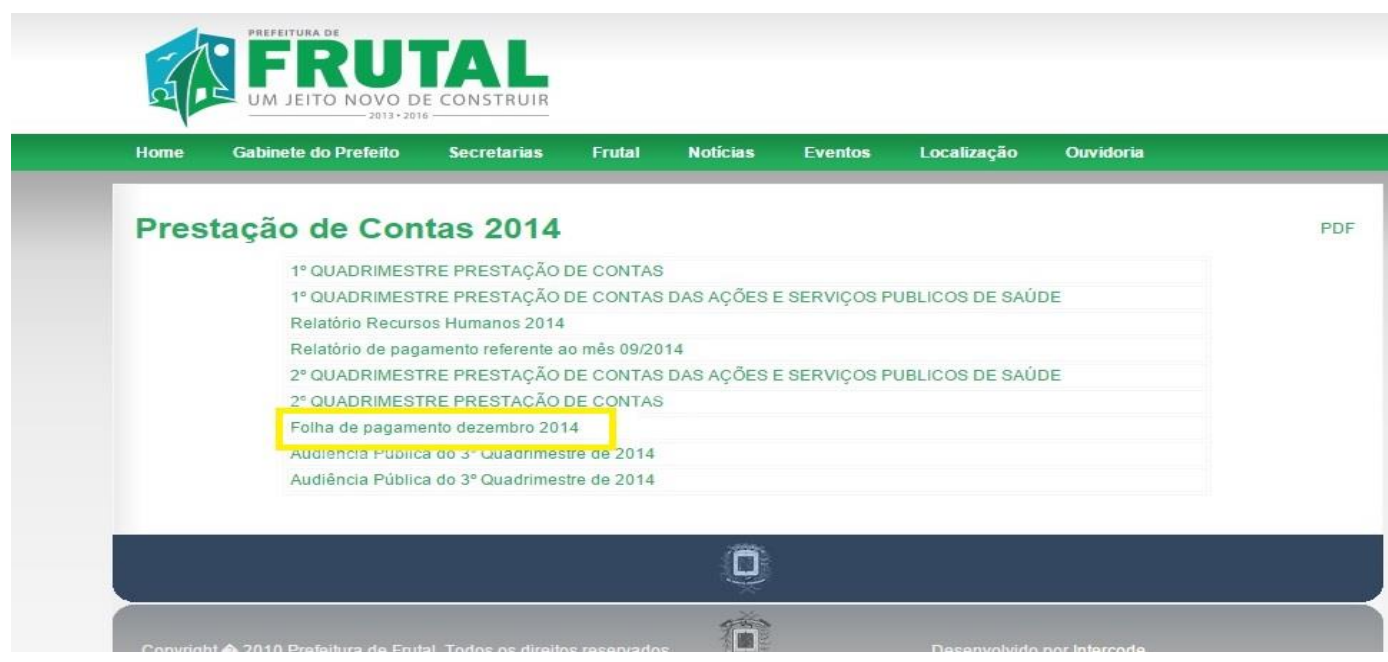

Fonte:http://www.frutal.mg.gov.br/Financas-e-Planejamento/prestacao-de-contas-

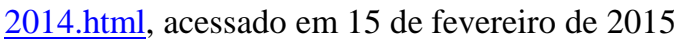


Nesta página, encontra-se disponibilizada somente a Folha de Pagamento do mês de dezembro do referido ano. Também o internauta não encontra qualquer justificativa para a não divulgação dos pagamentos efetuados aos servidores públicos e terceirizados nos demais 11 meses do ano.

Ainda com relação à Folha de Pagamento dos servidores públicos, nos dois meses que ela está disponível no site (Dezembro de 2014 e Janeiro de 2015), especificase somente o valor bruto dos salários, não constando descontos ou mesmo os acréscimos de horas-extras ou algum tipo de abono ou gratificação. Na Lei de Acesso à Informação, determina-se que sejam divulgados, no mínimo, os seguintes dados sobre cada servidor: número de identificação funcional; nome completo; CPF (ocultando os três primeiros dígitos e os dois dígitos verificadores do CPF); cargo e função; lotação; Regime Jurídico; jornada de trabalho; ato de nomeação ou contratação; respectiva data de publicação do ato; cargo efetivo ou permanente ou emprego permanente; órgão ou entidade de origem, no caso de servidor requisitado ou cedido e remuneração individualizada.

Figura 4 - Folha de Pagamento

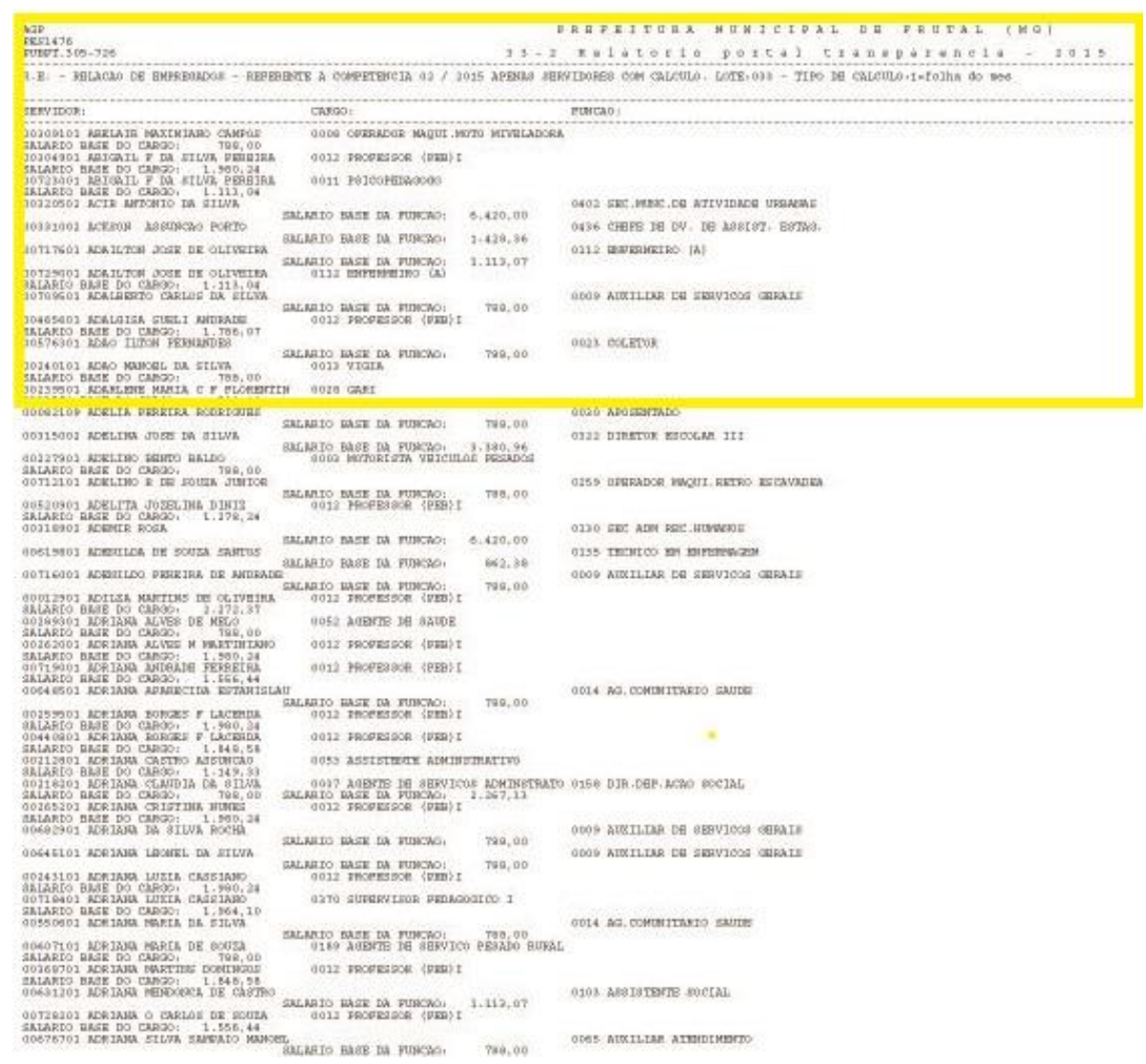

Fonte:http://www.frutal.mg.gov.br/images/P.transparenciaFolha022015RH.pdf, acessado em 20 de março de 2015. 
A forma como é disponibilizada a Folha de Pagamento dos Servidores é de difícil compreensão e constam apenas nome, cargo e salário bruto.

Também quando se analisou o tópico da área de Recursos Humanos, não foram encontrados dados referentes ao Plano de Carreira dos Servidores, com o detalhamento dos cargos e estrutura remuneratória. Oculta-se também os atos de provimento e vacância.

No sítio eletrônico não se identificou o SIC (Serviço de Informação ao Cidadão), espaço em que deveriam estar postadas informações pertinentes ao seu funcionamento - localização, horário de abertura ao público, nome dos servidores responsáveis pelo SIC, telefones e $e$-mails específicos para orientação e esclarecimentos de dúvidas, tais como sobre a protocolização de requerimentos de acesso à informação; a tramitação de solicitação de informação; nome da autoridade do órgão responsável pelo monitoramento da implementação da Lei de Acesso à Informação, no âmbito do órgão/entidade, conforme previsto no art. 40 da Lei em tela. Também deveria ser disponibilizado via on line um modelo de formulário de solicitação de informação para aqueles que queiram apresentar o pedido em meio físico (papel) junto ao SIC.

Outro tópico que não consta é o ícone Informações Classificadas. Nesta seção, deveriam estar expostas situações que foram classificadas como sigilosas nos últimos doze meses, com a disponibilização para download de formulários de pedido de desclassificação e de recurso referente a pedido de desclassificação. Conforme determinado no art. 29 da Lei de Acesso à Informação "a classificação das informações poderá ser reavaliada mediante provocação. Por isso, é necessário que os órgãos e entidades do Poder Executivo disponibilizem aos cidadãos formulários para pedido de desclassificação e interposição de recurso referente a pedido de desclassificação".

$\mathrm{Na}$ pesquisa, foi possível levantar que o sítio eletrônico não disponibiliza os endereços e telefones dos respectivos departamentos da Prefeitura, com horários de atendimento ao público. Nos preceitos da LAI, deveriam constar, além dos telefones e endereços de contato dos ocupantes dos principais cargos, a agenda de autoridades e os horários de atendimento dos órgãos/entidades.

Não se têm online dados gerais para acompanhamento de programas, ações, projetos e obras de órgãos e entidades do Governo Municipal (Art $8^{\circ}, \S 2^{\circ}$, inciso V).

Nos links da maioria das Secretarias constam apenas nome do secretário, endereço, $e$-mail e telefone. 
Figura 5 - Dados da Secretarias

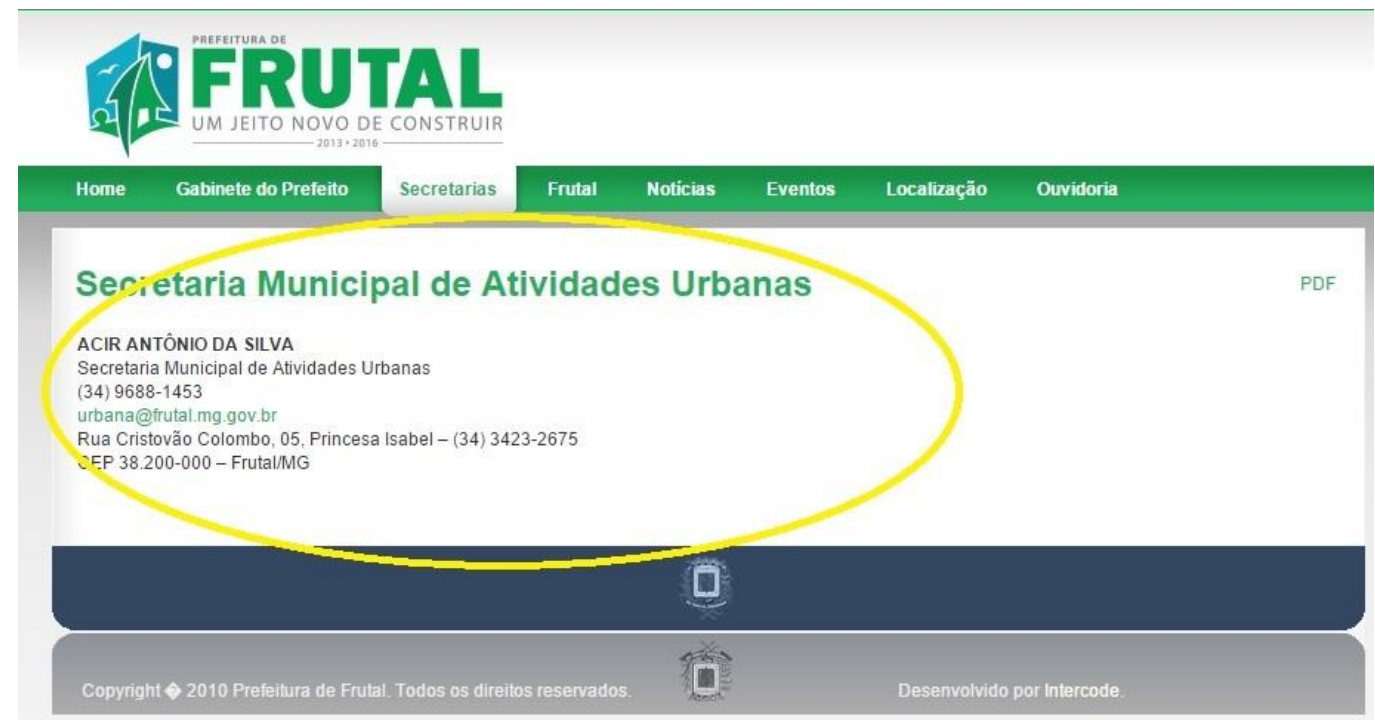

Fonte: http://www.frutal.mg.gov.br/Atividades-Urbanas/secretaria-municipal-de-atividades-urbanas.html, acessado em 8 de março de 2015;

Ao clicar nos links de cada secretaria, os munícipes vão encontrar na maioria deles, apenas o nome do secretário, contatos e a localização da sua secretaria.

O não cumprimento da Lei de Acesso à Informação (LAI), no sítio eletrônico da Prefeitura de Frutal, é constatado também nos seguintes tópicos:

- Não estão disponibilizados no portal os Termos de Convênio celebrados pelo Município, de forma a identificar o número do convênio, os nomes da concedente, as datas da celebração e da publicação do convênio, sua vigência, objeto, a situação do convênio, valor da transferência, valor da contrapartida e o valor pactuado (Art. $8^{\circ}, \S 2^{\circ}$, inciso IV).

- Não há disponibilização de informações relativas às despesas com passagens e diárias pagas pelo Município. Desta forma, não se permite que os cidadãos identifiquem o nome e o cargo do servidor que realizou a despesa, a origem e o destino da viagem, o objetivo da mesma e o meio de transporte utilizado.

- Não está acessível para consulta aos resultados de inspeções, auditorias, prestação e tomadas de contas pelos órgãos de controle interno e externo, incluindo prestação de contas de exercícios anteriores (art. $7^{\circ}$, inciso VII, b). 
Figura 6 - Sistema de Informações Fiscais

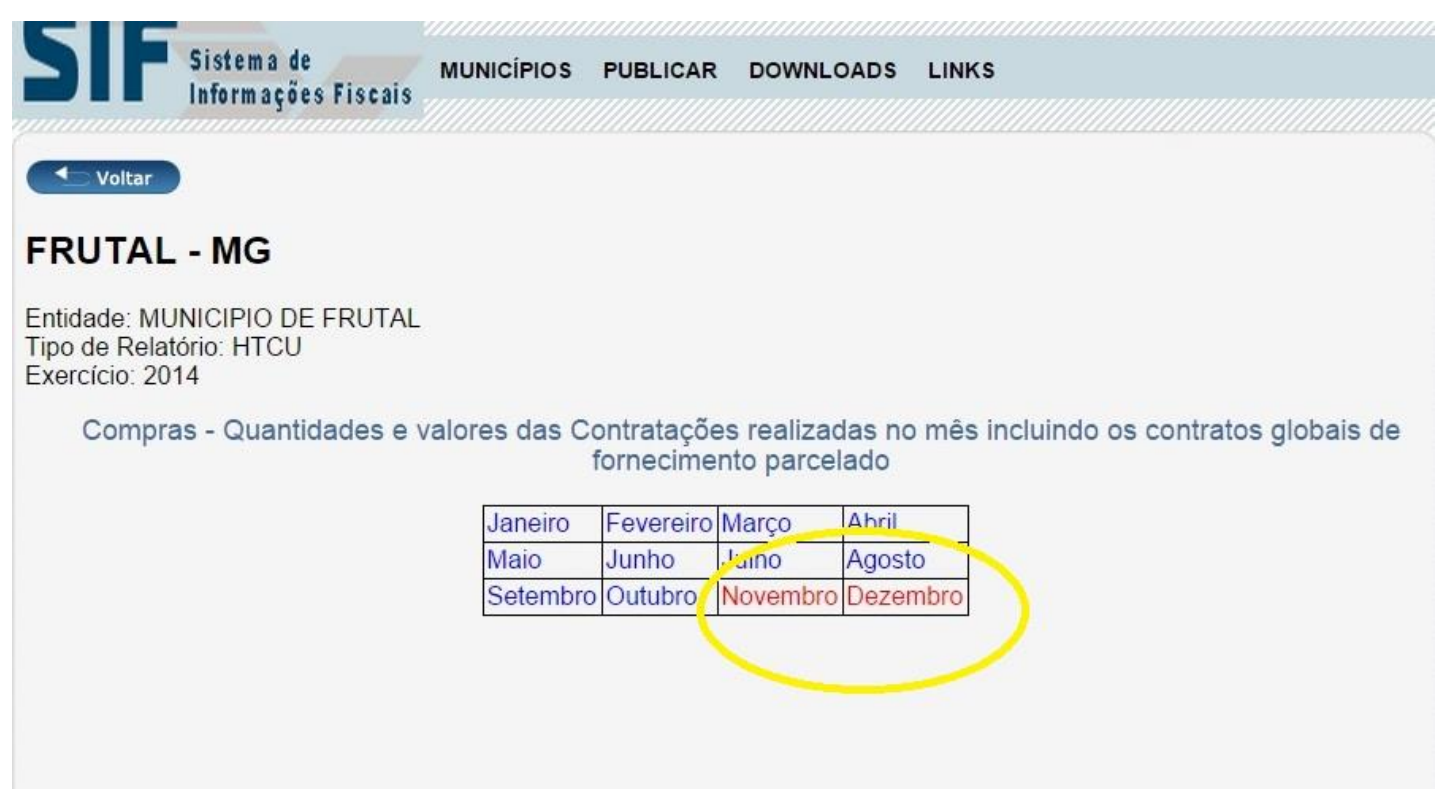

Fonte: http://sif.netgov.com.br/sif/, acessado em 15 de março de 2015.

Em 17 de março de 2015, a Prestação de contas dos meses de novembro e dezembro do ano anterior ainda não estavam disponibilizadas. Ou seja, enquanto as notícias promocionais têm atualizações quase que diárias, as prestações de contas ficam sem postagens por mais de 5 meses.

- Não estão acessíveis, no sítio eletrônico, o Plano Plurianual (PPA) e respectivos anexos, a Lei de Diretrizes Orçamentárias (LDO) e respectivos anexos e a Lei Orçamentária Anual (LOA) e respectivos anexos.

- Por via online, os munícipes também não têm acesso às informações relativas aos repasses ou transferências de recursos recebidos ou realizados pelo Município. (Art. $8^{\circ}, \S 2^{\circ}$, incisos II e III).

- Levantou-se a falta de um organograma da Prefeitura e de informações curriculares dos servidores comissionados que exercem os cargos de primeiro escalão. Não constam experiências profissionais, forma de contratação, funções exercidas e responsabilidades assumidas. Essa lacuna também se verifica na apresentação do prefeito municipal e do vice-prefeito. No que se determina na Lei, é obrigatória a apresentação da estrutura organizacional da Prefeitura, as competências, a base jurídica e as competências do órgão/entidade, inclusive regimentos internos, quando existirem e, a lista dos principais cargos e seus respectivos ocupantes, denominada "Quem é Quem" (Art. $8^{\circ}, \S 2^{\circ}$, inciso I). 
Figura 7 - Dados do Prefeito

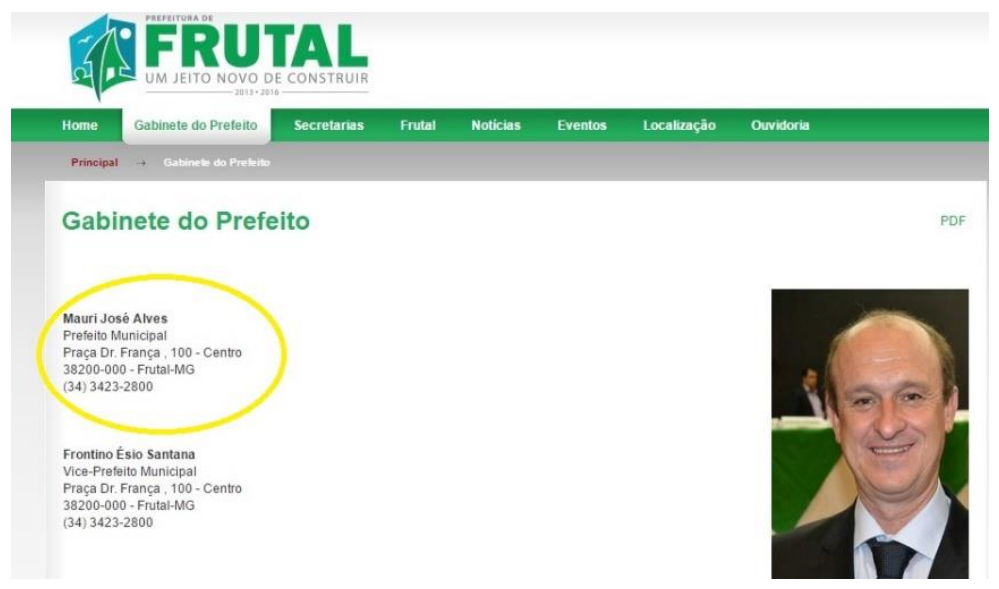

Fonte: http://www.frutal.mg.gov.br/gabinete-da-prefeita.html, acessado em 15 de março de 2015.

As informações sobre o Prefeito e Vice-prefeito resumem-se ao nome completo e endereço da Prefeitura. Neste link, não se disponibilizam qualquer tipo de informação que permita um conhecimento mais detalhado dos gestores.

\section{Conclusão}

No próximo dia 16 de maio de 2015, completam-se 03 anos da vigência da Lei 12.527/11. Mas, a sua implantação ainda está engatinhando, se analisarmos os dados levantados na pesquisa realizada no sítio eletrônico da Prefeitura Municipal de Frutal.

No contexto estudado, concluiu-se que a transparência ainda não é uma regra da Administração Pública brasileira, embora exista uma Lei clara com essa proposta.

Como foi relatado neste artigo, os avanços das Tecnologias de Informação e Comunicação (TICs) facilitam, em todos os sentidos, o processo de disponibilização de dados e interatividade com os munícipes. Mas, o que se conclui é que os serviços públicos de informações divulgados nos sítios eletrônicos são, na sua maioria, similares aos oferecidos pelo Poder público nos canais tradicionais, "são poucos os serviços inovadores desenhados, levando em consideração os recursos e o potencial da tecnologia" (CHAHIN et al, 2004).

No caso da Prefeitura Municipal de Frutal, é visivelmente constatado, que essas plataformas são pouco exploradas e, grande parte dos exíguos dados liberados, é postada como documentos escaneados. Isso, além de dificultar o entendimento do cidadão pela própria qualidade de visibilidade, os conteúdos são totalmente técnicos, em muitos casos com siglas, sem um glossário, com anexos que as decifre. 
Por não ser o foco da pesquisa, não se tem conhecimento se a Prefeitura Municipal de Frutal designou, como determina a Lei, uma pessoa responsável para o monitoramento da aplicação da Lei de Acesso à Informação. Mas, uma das falhas levantadas na pesquisa, é a não implantação do SIC (Serviço de Informação ao Cidadão), em que deveriam estar especificadas informações sobre: localização, horário de funcionamento, telefone, e-mails e nomes de servidores responsáveis pela manutenção do mesmo. Este seria o primeiro caminho para que os cidadãos conhecessem a aplicabilidade da referida Lei no âmbito da Prefeitura pesquisada.

O Governo Municipal não publica as respostas aos pedidos mais frequentes, o que é uma obrigação estabelecida pela LAI e que contribuiria para o cumprimento do papel de fiscalizador do munícipe. O que leva à compreensão que muitas vezes, a sociedade civil não é tão participativa e questionadora, porque não existe a transparência ativa, com informações disponíveis de maneira acessível a qualquer indivíduo.

O levantamento dos dados permitiu conhecer também o fato de que o sítio eletrônico da Prefeitura de Frutal é utilizado principalmente como meio de divulgação: informações sobre o Município, nas quais são vistas as histórias e a localização geográfica e notícias institucionais relacionadas às ações do Governo local.

Observou-se também que a internet não é explorada como recurso para disponibilizar o conjunto de serviços públicos municipais na forma online. Essa constatação corrobora a afirmativa anterior, na qual os dados mostram que a informação institucional é o conteúdo central do sítio eletrônico.

Neste aspecto, é possível analisar que o principal desafio para a administração pública é interno e não externo (TAKAHASHI, 2007). O que leva ao entendimento que a visão do gestor municipal é fator preponderante para o direcionamento das ações modernizantes que facilitem a transparência na administração municipal.

Em uma análise geral, o que se conclui da pesquisa, é que o sítio eletrônico estudado se ressente de uma maior interatividade, podendo-se inferir que as relações estabelecidas via internet são unilaterais. Não existe abertura para a accountability e para uma administração participativa. Fato que, embora se tenha muita tecnologia, ela não é potencializada em favor da transparência da gestão pública.

Entende-se a necessidade de pesquisas mais aprofundadas para compreender se realmente a falta de transparência nos sítios eletrônicos é proposital ou quais as dificuldades que estão travando o processo da construção de caminhos mais 
democráticos e participativos. Mas se atesta, que o cumprimento da LAI não é uma preocupação dos departamentos que alimentam o sítio eletrônico da Prefeitura de Frutal. Nota-se claramente, que as atualizações acontecem, com frequência em tempo contextual, no link Notícias, onde se percebe claramente, que os textos ali postados são de caráter publicitários e promocionais. Não existe por parte da Assessoria de Comunicação da instituição estudada, o entender que a transparência é propulsora da cidadania, participação e interação, que é o tripé que deve mover a comunicação pública.

\section{Apêndice}

Planilha para anotação das análises de dados pesquisados no sítio eletrônico da Prefeitura Municipal de Frutal

\begin{tabular}{|c|c|c|c|}
\hline Data da pesquisa & Item analisado & Sim/Não & Observações \\
\hline & Portal Transparência & & \\
\hline & Licitações & & \\
\hline & $\begin{array}{l}\text { Informações sobre os serviços } \\
\text { municipais oferecidos aos cidadãos }\end{array}$ & & \\
\hline & $\begin{array}{l}\text { Informações sobre projetos e seus } \\
\text { andamentos }\end{array}$ & & \\
\hline & $\begin{array}{l}\text { Informações } \\
\text { Administrativas/Secretarias }\end{array}$ & & \\
\hline & Informações sobre o prefeito & & \\
\hline & $\begin{array}{l}\text { Divulgação das contas públicas e } \\
\text { balanços orçamentários }\end{array}$ & & \\
\hline & $\begin{array}{l}\text { Informações de repasses ou } \\
\text { transferências de recursos recebidos ou } \\
\text { realizados pelo Município }\end{array}$ & & \\
\hline & $\begin{array}{l}\text { Informações de convênios celebrados } \\
\text { pelo Município }\end{array}$ & & \\
\hline & $\begin{array}{l}\text { Disposição detalhada da Folha de } \\
\text { Pagamento da Prefeitura }\end{array}$ & & \\
\hline
\end{tabular}




\begin{tabular}{|c|c|c|c|}
\hline \multirow[t]{3}{*}{ Data da pesquisa } & \multirow{2}{*}{$\begin{array}{l}\text { Item analisado } \\
\text { Dados sobre gasto com viagens, } \\
\text { diárias e finalidades }\end{array}$} & \multirow[t]{2}{*}{ Sim/Não } & \multirow[t]{2}{*}{ Observações } \\
\hline & & & \\
\hline & $\begin{array}{l}\text { Estrutura organizacional } \mathrm{e} \\
\text { organograma da Prefeitura }\end{array}$ & & \\
\hline & $\begin{array}{l}\text { Horários de atendimento ao público, } \\
\text { localidade e telefone de todos os } \\
\text { órgãos ligados à Prefeitura }\end{array}$ & & \\
\hline & Facilidade de Navegação do site & & \\
\hline & Atualizações diárias das informações & & \\
\hline & $\begin{array}{l}\text { Publicação do Plano Plurianual (PPA), } \\
\text { Lei de Diretrizes Orçamentárias } \\
\text { (LDO) e Lei Orçamentária Anual } \\
\text { (LOA) }\end{array}$ & & \\
\hline & $\begin{array}{l}\text { Relatório resumido da Execução } \\
\text { Orçamentária ao final de cada bimestre }\end{array}$ & & \\
\hline & 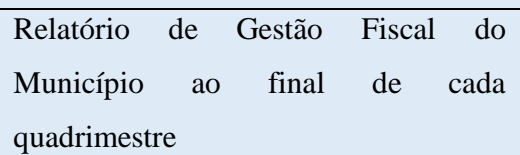 & & \\
\hline & $\begin{array}{l}\text { Prestação de contas anual entre ao } \\
\text { TCE, com seu respectivo parecer }\end{array}$ & & \\
\hline & & & \\
\hline
\end{tabular}

Fonte: Elaborado pela pesquisadora

\section{Referências}

BRASIL. Presidência da República. Casa Civil. Lei No 12.527, DE 18 DE NOVEMBRO de 2011. Disponível em http://www.planalto.gov.br/ccivil_03/_ato20112014/2011/Lei/112527.htm. Acesso em 14 janeiro de 2015

BRASIL. Presidência da República. Casa Civil. Constituição da República Federativa do Brasil de 1988. Disponível em http://www.planalto.gov.br/ccivil_03/Constituicao/Constituicao.htm\#art216§2. Acesso em 14 de janeiro de 2015.

BRASIL. Presidência da República. Casa Civil. Lei Complementar $\mathbf{N}^{\circ}$ 101, DE 4 de Maio de $2000 . \quad$ Disponível em http://www.planalto.gov.br/ccivil_03/Leis/lcp/lcp101.htm. Acesso em 14 de janeiro de 2015.

CHAHIN, Ali et al. e-gov.br a próxima revolução brasileira: eficiência, qualidade e democracia - o governo eletrônico no Brasil e no mundo. São Paulo: Prentice-Hall, 2004. 
CRESWELL, John W. Projeto de pesquisa: Métodos Qualitativos, Quantitativos e Mistos. 2.ed. Porto Alegre: Artmed, 2007.

CUNHA, Maria Alexandra; FREY, Klaus; DUARTE, Fábio. Governança local e as tecnologias de informação e comunicação. Curitiba: Champagnat, 2009.

FERREIRA, Jeová. Original História de Frutal. Frutal: Oficinas de Artes Iara Lins, 2002.

FOLHA DE S. PAULO. Disponível em http://www.folha.uol.com.br/ Acesso em 16 de março de 2015.

GONÇALVES, Carlos Alberto; MEIRELLES, Anthero de Moraes. Projeto e relatórios de pesquisa em Administração. São Paulo: Atlas, 2004.

HISTÓRIA E CULTURA DA ÁGUA EM FRUTAL. Disponível em http://issuu.com/historiaeculturadaagua/docs/mapeando_a_hist_ria_de_frutal_-_de.

Acessado em 4 de fevereiro de 2015.

INSTITUTO BRASILEIRO DE GEOGRAFIA E ESTATÍSTICA - IBGE. Disponível em: http://cidades.ibge.gov.br/xtras/perfil.php?codmun=312710. Acesso em 15 de janeiro. 2015.

FRUTAL, Prefeitura Municipal. Disponível em http://www.frutal.mg.gov.br/ Acesso em 18 de dezembro de 2014; 17 de março de 2015

RICHARDSON, Roberto J. et al. Pesquisa Social: Métodos e Técnicas. 3.ed. São Paulo: Atlas, 2008.

SELLTIZ et al. Métodos de pesquisa nas relações sociais. São Paulo: E.P.U, 1975.

TAKAHASHI, Tadao. Rumo a um e-Brasil: pontos a ponderar. In: KNIGHT, Peter Titcomb; FERNANDES, Ciro Campos Christo; CUNHA, Maria Alexandra (orgs). edesenvolvimento no Brasil e no mundo: subsídios e Programa e-Brasil. São Caetano do Sul, SP: Yendis Editora, 2007, p.222- 272

TRIVIÑOS, Augusto Nibaldo Silva. Introdução à pesquisa em ciências sociais: a pesquisa qualitativa em educação. 16. reimp. São Paulo: Atlas, 2008.

UMEOKA, Emilio. Potenciais realizados. In: FERRER, Florência; SANTOS, Paula (Orgs.). e-government: o governo eletrônico no Brasil. São Paulo: Saraiva, 2004, p. 87-92. 